\title{
BMJ Open Work-health-personal life conflicts in naive patients with chronic hepatitis B receiving initial treatment in China: a qualitative study
}

\author{
Yingjing Zheng, ${ }_{1,2}^{1,}$ Lin Zhu, ${ }^{1,2}$ Donald Patrick, ${ }^{3}$ Ying Li, ${ }^{4}$ Fengjiao Xu, ${ }^{1,2}$ Li Zhang, ${ }^{1,2}$ \\ Mengna Song, ${ }^{1,2}$ Xiao Cheng, ${ }^{1,2}$ Boyan Chen, ${ }^{1,2}$ Ying Chen, ${ }^{1,2}$ Xiaoyang Lu, ${ }^{2}$ \\ Hongmei Wang (1) ${ }^{1,2}$
}

To cite: Zheng Y, Zhu L, Patrick D, et al. Workhealth-personal life conflicts in naive patients with chronic hepatitis B receiving initial treatment in China: a qualitative study. BMJ Open 2020;10:e035688. doi:10.1136/ bmjopen-2019-035688

- Prepublication history and additional material for this paper is available online. To view these files, please visit the journal online (http://dx.doi.org/10. 1136/bmjopen-2019-035688).

YZ and LZ are joint first authors.

Received 12 November 2019 Revised 30 July 2020 Accepted 03 August 2020

Check for updates

(C) Author(s) (or their employer(s)) 2020. Re-use permitted under CC BY-NC. No commercial re-use. See rights and permissions. Published by BMJ.

For numbered affiliations see end of article.

Correspondence to Professor Hongmei Wang; rosa@zju.edu.cn

\section{ABSTRACT}

Objectives People with chronic hepatitis B (CHB) perform sick roles, work roles and personal roles simultaneously. At times, role conflicts arise because of failure to meet the expectations of different roles. Role conflicts may increase dissatisfaction in work and family and impair their physical and mental health. This study aimed to explore the perceptions of role conflicts of treatmentnaive patients with $\mathrm{CHB}$ in work, personal and sick roles, together with ameliorating factors in the Chinese cultural context.

Design A qualitative descriptive study. Semistructured interviews were used to collect the experience of workhealth-personal life conflicts (WHPLCs), and a brief questionnaire was used to collect demographic and clinical information. SPSS V.21.0 was used for descriptive analysis and Dedoose (V.7.5.9) was used to code and analyse interview transcripts. This study selected six cities with different socioeconomic levels in Zhejiang Province, China. Then, researchers chose one tertiary hospital from each city as the study site, so a total of six tertiary hospitals were involved.

Participants We recruited 32 patients with CHB (59.38\% male) who had just started antiviral therapy for no more than three months. Participants were within the age range of 19-57 years, and the average age was $36.03(S D=9.56)$ years.

Results Participants noted that having CHB influenced their daily life and intersected with work and personal roles, therefore causing role conflicts. Role conflicts focused on three types: time-based conflicts, strain-based conflicts and behaviour-based conflicts. The contextual factors contributing to role conflicts were identified, including personal characteristics, financial strain, traditional social roles and work environment.

Conclusions These findings enhance our understanding of the WHPLCs experience of treatment-naive patients with CHB in China. Our findings suggest that multidimensional role conflicts should be taken into account in the intervention design and psychological counselling to improve role balance and well-being among patients with CHB.

\section{Strengths and limitations of this study}

- This study was designed to investigate the workhealth-personal life conflicts experienced by treatment-naive patients with chronic hepatitis B (CHB) and relevant factors in the Chinese context.

- Compared with past studies concentrating on individuals living with chronic noncommunicable diseases, this study focused on treatment-naive patients with $\mathrm{CHB}$. This population just started antiviral therapy and played a sick role and other social roles simultaneously, and thus might be more likely to encounter multiple role conflicts in different life spheres.

- Participants were recruited with the help from doctors, which means that patients with good adherence were more likely to be included than those with poor adherence. Therefore, this is a purposive sample.

- The qualitative methods used in this study can only reveal the conflicts and possible associations but not the magnitude and causality of these associations, for which further studies are needed.

\section{INTRODUCTION}

Role conflict was defined by Kahn et $a l^{1}$ as a simultaneous occurrence of two or more sets of pressures such that compliance with one makes it more difficult to comply with another. If a person is unable to adjust his or her behaviour to comply with the expectations of different roles, he or she is likely to experience multiple role conflicts. Since the worksite and family are two central institutions in most people's lives, interactions of work and family roles have commonly been reported in previous studies. ${ }^{2-5}$ For instance, an 'ideal' employee is expected to be at work at set times, focused only on the tasks at hand, responsive only to demands of supervisors and available for long working hours but unhampered by other responsibilities, such as 
children and housework as the demands of family roles, ${ }^{6}$ and vice versa. With energy and time being inadequately devoted to family roles, ${ }^{7-10}$ the family relationships are negatively affected. However, insufficient investment in the work roles can result in job loss, which may adversely affect the quality of life of the individual and of his or her whole family. ${ }^{4}$ In addition, a number of studies also found that experiencing role conflicts could cause distress, ${ }^{11} 12$ and sleep problems, ${ }^{13}$ and increase dissatisfaction in work and family, ${ }^{14}$ which ultimately led to poor physical and mental health. ${ }^{51215-18}$

From Parsons' point of view, being sick is also an important role ${ }^{19}$ but little attention has been paid to it in those studies on role conflicts. When perceiving themselves as sick, individuals need to meet additional specific expectations, involving committing to the goal of recovery, seeking medical treatment and complying with doctors' advice. ${ }^{20}{ }^{21}$ Previous studies indicated that it was hard for patients with chronic diseases to confront competing expectations of an ongoing 'sick role' and the the expectations of their usual roles, such as employment, parenting, intimate relationships, leisure and community involvement. ${ }^{22} 23{ }^{24}$ Difficulties in balancing sick roles and other preillness normative roles may trigger role conflicts and further result in negative outcomes in individuals' health, work and personal life domains. ${ }^{22}$ 23 25-27 The maladjustment of sick roles was associated with poor adherence to treatment, which might accelerate disease progression. ${ }^{28-30}$ In addition, Frone $e t a \hat{l}^{31}$ found that role conflicts were related to increased levels of depression, poor physical health and heavy alcohol consumption. Gignac et $a l^{26}$ found that people with arthritis have to deal with symptoms such as pain and fatigue during work time. They also had activity limitations with work tasks which implied work-health-personal life conflicts (WHPLCs) and highlighted the necessity of the further exploration of health and work context factors that might improve role balance. ${ }^{32}$

Chronic hepatitis B (CHB) is a kind of chronic infectious disease, and approximately $12 \%-15 \%$ of patients with CHB develop liver cirrhosis within 5 years. ${ }^{33}$ As a populous nation and a highly endemic area, China has approximately 93 million people living with hepatitis B surface antigen positivity and 20 million patients with active CHB. ${ }^{34}$ Hepatitis B virus (HBV) infection could be asymptomatic for many years, and only continuous monitoring is recommended for patients with $\mathrm{CHB}$ who do not meet the criteria for treatment. ${ }^{35}$ However, when significant inflammation and fibrosis exist with persistently abnormal alanine aminotransferase levels and evidence of high-level HBV replication, antiviral therapy is necessary. In addition, counselling based on the 'Hepatitis B Guidelines' provided by the American Association for the Study of Liver Diseases and the WHO is also given by physicians to promote the necessary lifestyle changes. ${ }^{37} 38$ These guidelines include alcohol reduction, smoking cessation, a healthy diet and physical activity. Hence, treatmentnaive patients with CHB start to play their sick roles with rights such as accessibility to treatment and obligations such as following physicians' suggestions.

Although multiple role conflicts have been well reported in chronic noncommunicable disease conditions, for example, arthritis, ${ }^{22} 23262732{ }^{39-41}$ studies focusing on individuals living with chronic infectious diseases are limited. This population, with lower social function and mental health, ${ }^{38} 42-44$ and more disease-related stigma/discrimination, ${ }^{45}$ also face challenges in fulfilling multiple role demands. Chinese patients with CHB reported worse quality of life than those in other countries demonstrated by stigma/discrimination in employment (eg, career development), marriage (eg, building intimate relationships) and education (eg, continuing impact of past legislation on educational choices). ${ }^{2546} 47$ Patients with CHB in China may not easily follow suggestions from clinicians due to limited time, energy and financial and psychological resources and may thus experience role conflicts among work, health and personal life. ${ }^{48}{ }^{49}$ The potential gaps among an 'ideal' employee, an involved family/ friend and a patient following doctors' advice can serve as a significant conflict source.

The purpose of this qualitative study was to explore the unique multiple role conflicts experienced by naive patients with CHB receiving initial antiviral therapy in the Chinese context. The related contextual factors contributing to role conflicts were further analysed, which may inspire future interventions to help patients manage and improve role balance.

\section{METHODS}

\section{Study design}

In this qualitative descriptive study, semistructured interviews were conducted with treatment-naive patients with CHB to gain their experience of how the disease affects their daily life and to determine the WHPLCs they may face and related factors. Semistructured interviews were chosen considering the advantage of achieving rich, in-depth accounts of participants' feelings, experiences and perspectives. In addition, previous studies have found that patients with CHB usually suffer stigma/discrimination and are reluctant to disclose that they have the disease. ${ }^{47} 50$ Therefore, one-on-one interviews are particularly appropriate in this study to collect disease-related sensitive issues. ${ }^{51}$ Demographic and clinical information was collected via a brief questionnaire.

\section{Settings}

The settings were selected via stratified sampling. We first selected six cities with different socioeconomic levels in Zhejiang Province, China (cities: high level: Hangzhou, Ningbo; medium level: Yiwu, Huzhou; low level: Taizhou, Quzhou). Then we chose one tertiary hospital from each city as the study site, and a total of six tertiary hospitals were involved. All interviews were conducted in a private room at the hospital's hepatitis clinic. 


\section{Participants}

Treatment-naive patients with $\mathrm{CHB}$ who started antiviral therapy with oral nucleoside drugs for no more than 3 months prior to recruitment. Individuals who had a history of any serious and end-stage diseases or drug and alcohol abuse were excluded. Eligible patients with CHB were recruited considering maximum variation (age, gender and education level) to capture a socioculturally diverse sample. Participants were recruited until three consecutive interviews provided no more new information, which meant theoretical saturation was achieved. Ultimately, 32 participants were included in this study.

\section{Data collection}

The semistructured interview guide (see online supplemental appendix 1) was developed based on the literature regarding role conflicts in chronic disease conditions and the illness experience of patients with CHB. This interview guide was modified based on feedback from an experienced doctor for infectious diseases and pilot interviews. Questions mainly focused on the patient's life, goals, perceptions and worries that were associated with CHB in the work, health and personal life domains after diagnosis when on treatment.

The interviews were carried out from July to November 2016. Four well-trained and experienced researchers recruited the participants and explained the study objectives and methods briefly with the assistance of clinical professionals. Before the interviews started, the patients were told that their participation was completely voluntary and that all information obtained would be kept strictly confidential. Written informed consent was also obtained from each participant. Only the interviewer and participant were present during the interview. We started the interviews with an open question (eg, 'How does your CHB disease affect your daily life?') and collected data following the semistructured interview guide. Each interview was audio-taped and lasted for approximately 40 minutes.

\section{Data analysis}

EpiData V.3.1 (The EpiData Association, Denmark, Europe) was used to input, verify and organise the demographic information and disease characteristics. SPSS V.21.0 was used for descriptive analysis. Audio-taped interviews were transcribed verbatim into written medium in Word documents. The participants' tone (eg, sighing), expressions (eg, crying), motions (eg, thinking and being silent) and other visual information (eg, facial expression) were recorded as well. Unclear voices and incoherent narratives in the recordings were double-checked for accuracy. The final transcripts were imported into Dedoose V.7.5.9 (SocioCultural Research Consultants, Los Angeles, California, USA) for extraction of themes and were coded by two researchers independently. All data were analysed anonymously to protect participants' identities. An inductive thematic analysis method was used to analyse the data. The emerging themes were identified based on meticulous and systematic reading and coding of the transcripts (see in online supplemental appendix 2). Fragments that elicited different opinions among researchers were discussed by the research team to reach a consensus.

\section{Patient and public involvement}

The participants were not involved in the design, recruitment and conduct of this study. A $100 \mathrm{CNY}$ (US\$1 $\approx 6.7$ $\mathrm{CNY}$ ) reimbursement was given to each participant for their time and travel cost after the interviews.

\section{RESULTS}

\section{Characteristics of participants}

Participants were within the age range of $19-57$ years, and the average age was $36.03(\mathrm{SD}=9.56)$ years. There were 19 male participants $(59.38 \%)$, and 24 participants $(75.00 \%)$ were married or cohabiting in a romantic or sexual relationship. Most participants $(87.50 \%)$ were living with others (lovers, family or friends), had a junior high school education $(34.38 \%)$ and had a full-time job $(68.75 \%)$. Eight participants $(25.00 \%)$ reported that their annual household income per capita was less than $24000 \mathrm{CNY}$, and 15 participants $(46.88 \%)$ rated their current health as fair. Fatigue was the most often reported symptom experienced by a majority of the patients with $\mathrm{CHB}$ in the past 6 months (see table 1 ).

\section{Types of WHPLCs}

The impacts of CHB on participants linked with WHPLCs could be classified into 11 subthemes in accordance with Greenhaus and Beutell's model of role conflicts: timebased conflicts, strain-based conflicts and behaviourbased conflicts ${ }^{52}$ (see figure 1).

\section{Time-based conflicts}

Time-based conflicts occur when an individual could not be physically and psychologically present within multiple roles simultaneously (eg, incompatibility of time in work, rest and housekeeping), which were acknowledged by participants as a key type of WHPLCs.

From the interviews, participants reported that their work roles were generally demanding (like most jobs requiring excessive work time), while enough rest and fatigue avoidance were necessary for patients with CHB in treatment based on doctors' advice. Twelve participants mentioned that they had been asked to work overtime. Five of them refused to work for extra time considering the impact on their disease status, while the other five participants who could not refuse working overtime struggled with their worries about $\mathrm{CHB}$ and pressures from work: 'I don't want to work for extra hours because of the disease $[\mathrm{CHB}]$. But when we were busy, everyone was there and worked overtime, how can I ask to leave. It [asking to leave] was impossible' (33201, female). Correspondingly, another issue identified by participants was that time-based conflicts may influence their job choice. 
Table 1 Demographic and disease characteristics of participants $(n=32)$

\begin{tabular}{|c|c|c|c|c|c|}
\hline Variables & $\mathbf{N}$ & Percentage & Variables & $\mathbf{N}$ & Percentage \\
\hline Age (years) & & & Annual household income per capita (CNY) & & \\
\hline$<30$ & 8 & 25.00 & $\leq 24000$ & 8 & 25.00 \\
\hline $40-49$ & 10 & 31.25 & $\geq 56000$ & 9 & 28.12 \\
\hline$\geq 50$ & 2 & 6.25 & Self-rated health & & \\
\hline Male & 19 & 59.38 & Very good & 4 & 12.50 \\
\hline Female & 13 & 40.62 & Good & 6 & 18.75 \\
\hline Marital status & & & Fair & 15 & 46.88 \\
\hline Married/cohabitation & 24 & 75.00 & Poor & 6 & 18.75 \\
\hline Divorced/separated & 3 & 7.37 & Other diseases & & \\
\hline Living alone & 4 & 12.50 & Other & 5 & 15.63 \\
\hline Educational attainment & & & None & 23 & 71.88 \\
\hline Elementary school or below & 3 & 9.38 & Disease symptoms & & \\
\hline Middle school & 11 & 34.38 & Fatigue & 24 & 75.00 \\
\hline High school & 5 & 15.62 & Nausea & 8 & 25.00 \\
\hline Junior college & 4 & 12.50 & Anorexia & 11 & 34.38 \\
\hline College or above & 9 & 28.12 & Low fever & 2 & 6.25 \\
\hline Employment status & & & Other & 1 & 3.12 \\
\hline
\end{tabular}

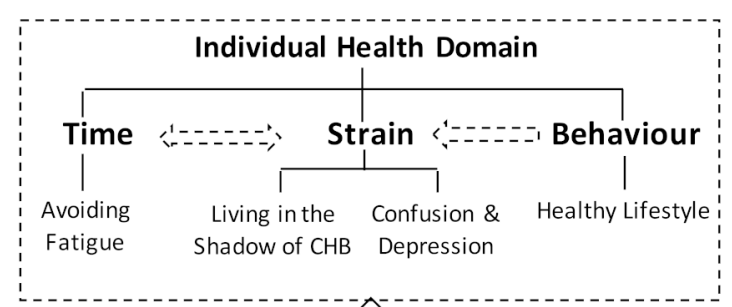

\section{Conflicts}<smiles></smiles>

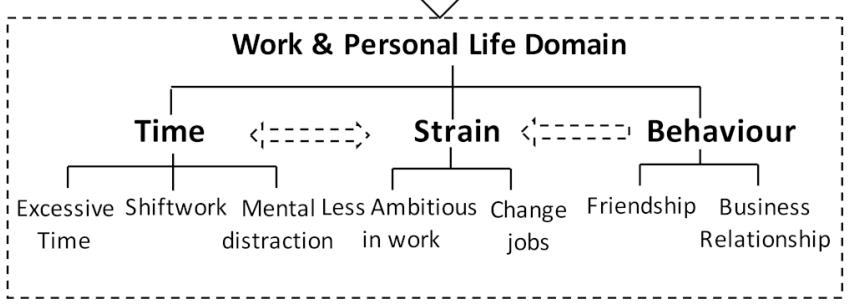

Figure 1 Three types of WHPLCs and the association.

CHB, chronic hepatitis B; WHPLCs, work-health-personal life conflicts.
For example, shiftwork in China usually requires one to work continuously for more than 8 hours and/or to be on night duty, which is difficult for participants to take. 'Some factories are running on two shifts, twelve hours.... Even though such factories provide higher pay, I dare not work there because I know I am not strong enough. In addition, staying up late is definitely not good for my liver' (12201, female).

Mental distraction at work caused by non-fulfillment of obligations of the sick role was illustrated by three participants, which generally resulted in less involvement in work. Six participants expressed their consideration of potential or actual fatigue from CHB, for example, 'I've felt tired recently... What I consider most is how to reduce workload. I don't seem to have anything else to think about [in work]' (31203, female). 'What I'm most dissatisfied with is my poor physical condition. I avoid working hard because I feel worried about the future consequences (related to CHB)' (12101, male). 
Moreover, time-based conflicts existed between the family role and sick role as well: 'About half a year ago, I found that my body became worse and felt tired, but I was too busy building a house for my family to see the doctor [for periodic review]' (22101, male). 'Sometimes I still need to do housework when I come back home [from work]; this made me feel [tired]. Anyway I just want to have a rest, without any interests in leisure activities outside with friends' (42201, female).

These time-based conflicts may lead to side effects on career development and personal life involving performing family and friend roles. They might feel stressed because they could only commit to limited obligations in specific roles, together with feeling guilty and remorseful, as they were unable to spend time on work/ family or with friends. Participants facing such situations might also experience strain-based WHPLCs.

\section{Strain-based conflicts}

Strain-based conflicts occur when strain and fatigue associated with one role crossover into another role and affect performance of that other role. ${ }^{31}$ When mental and emotional strain stems from a sick role and there is a spillover of negative emotions from one domain to the another (eg, from personal health to work), many participants experienced strain-based conflicts that manifested as living in the shadow of CHB as well as confusion and anxiety.

Living in the shadow of CHB was identified by participants as being generated from sick roles and spreading to work-related roles. The majority of participants reported that they had experienced discrimination because of the social stigma of HBV. Nine participants noted that they faced discrimination when they applied for a job and four of them shared their failed job interview experiences: 'There is a shadow in my heart [speaking in a low voice]. And it (CHB) is not particularly good for our jobs. Nowadays, when I am looking for a job, I will feel a headache once I hear words like "healthy body" and so on (wry smile)' (21104, male). If someone suffers such a situation repeatedly, he or she might have a profound memory of CHB-related stigma, resulting in a change in cognition and coping style for a specific thing like looking for job, which is manifested as discouragement or strain, especially in the period when they were just starting antiviral therapy. In addition, living in the shadow of CHB was manifested as participants giving up promotion opportunities (work role) due to their self-discrimination in the sick roles. Fifteen participants shared the opinion that CHB made them less ambitious in their careers, 'After I had this disease, I gave up a lot of opportunities... Because of this disease... I lost interest in fighting for some positions... I know I shouldn't be too tired, so I gave up all the chances.... Well, as a patient, I don't have to be so ambitious at work' (31203, female).

Confusion and anxiety were reported by eight participants when they had difficulty changing work to balance the demands of the health and work domains, and these emotions even flowed to the family domain, 'Considering fatigue, and I have to work for 13 hours a day. Thus, I want to change my job, but I have no suitable jobs to change to. These matters make me confused now [chuckles]' (31202, male). Meanwhile, this participant was anxious and pressured as a father because he had to raise three children, with a low annual household income per capita.

\section{Behaviour-based conflicts}

Behaviour-based conflicts refer to various behavioural expectations attached to work, health and personal life domains and the incapacity to adjust one's behaviour to meet these expectations within each life domain.

Ten participants reported that healthy lifestyle achievement was sometimes incompatible with work and/or personal life. Social interaction in work or personal life may require a person to energetically engage in social activities that are usually accompanied by alcohol consumption, smoking, and so on, in the Chinese context. 'At least now, making friends requires smoking, drinking and feast activities... I dared not drink too much. But if I don't drink much, others will feel I am not friendly and sincere. So making [especially business] friends is most seriously influenced by this disease [CHB]' (12101, male), 'He [the doctor] advised me not to drink and smoke. And he gave me many suggestions about diet. However, to be honest, it is hard to resist. Unless I don't work, there is no way' (12202, male).

Four participants chose to reduce social activities to avoid such conflicts, but this choice did not help them resolve conflicts and was even adverse in balancing demands from each life sphere. One said, 'In social situations like a party, it is impolite to refuse drinking. So I prefer not to participate because drinking is harmful for CHB. [However,] Sometimes I would offend some people [friends or business partners] by declining parties [sigh]' (11101, male).

\section{Associations in three types of conflicts}

Through the interviews, it is not hard to find that timebased and strain-based conflicts can sometimes be interchangeable, especially in the work domain. For treatment-naive patients with $\mathrm{CHB}$, both types of conflicts are related to the barrier of changing jobs and are easily influenced by work (time, intensity and so on) and society (stigma and so on), while behaviour-based conflicts are more influenced by specific competencies and the social context. There was also qualitative evidence in our study showing that unbalanced behaviour-based conflicts may result in psychological health problems and thence strainbased conflicts. 'Playing with friends requires drinking, and such opportunity is not much, only once or twice a year. But now it seems that I cannot even drink once, which means losing the pleasure of drinking with my friends' (22102, male). 'It (CHB) impacts making friends most significantly, which caused poor mental health. If I want to make a friend, he will not be satisfied until I get 


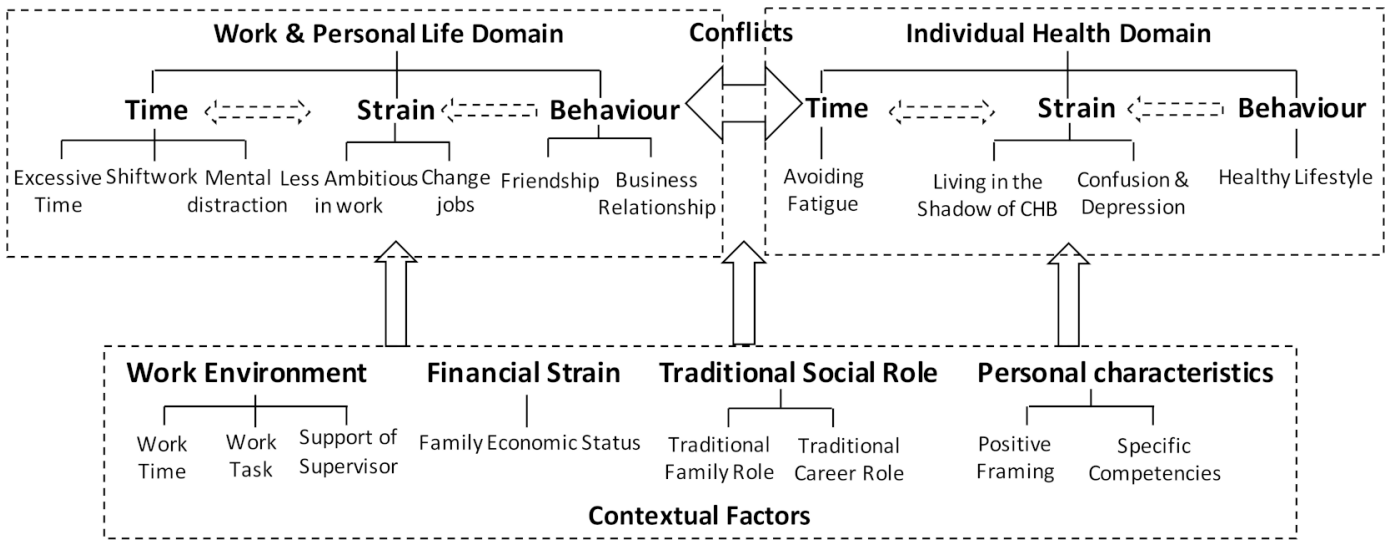

Figure 2 Contextual factors of WHPLCs. WHPLCs, work-health-personal life conflicts.

drunk, because he thinks that drinking a lot will show my sincerity' (12101, male).

\section{Contextual factors}

For each type of WHPLCs, participants noted some contextual factors alleviating their role conflicts. Contextual factors include personal characteristics, financial strain, traditional social role and work environment. Eight subthemes of these four themes were clarified (see figure 2).

\section{Personal characteristics}

Positive framing was identified as a common coping strategy used to adapt to a long-term sick role and thereby helps to reduce strain-based conflicts. As one stated, 'Because I am a positive person. I am also openminded... Well, I can accept it [CHB] calmly and live with it... Although this disease [CHB] is a burden in my heart' (11103, female). The interviewer also found this participant reading a book called Your Mind Can Heal Your Body, which guided patients on how to control the negative emotions and release themselves from strain and depression during the disease process.

Three participants reported that they used their specific competencies, including effective problem-solving skills and social skills to dissolve behaviour-based conflicts. For example, one mediated behaviour-based conflict by giving an excuse for abstaining rather than telling the truth, ' $\mathrm{Q}$ : Well, what kind of reason will you use to tell them you do not drink? A: Alcohol allergy' (13303, male). Such a method can maintain their good living habits without forcing them to refuse others bluntly, which can in turn help reduce their mental strain.

\section{Financial strain}

Financial strain among treatment-naive patients and their families was frequently mentioned in strain-based conflicts, which influenced health-seeking behaviour (eg, by delaying treatment) and job selection.

Eleven participants faced conflicts related to financial strain. Considering rough family economic status, five participants addressed that they were worried about the cost of lifelong treatment, which was why some of them were not willing to take antiviral drugs. A participant noted, 'The economic condition of my family is not good. I cannot afford medicine... So I was reluctant to take medicine... If I took the antiviral drug at that time, I would not have developed into CHB now' (12201, female). When a conflict exists between individual health and family financial status, some Chinese people usually value their family roles more than their sick roles. However, as a result of delayed treatment, aggravation of their illness made participants regretful and stressed. In addition, four participants wanted to change to a more relaxing job but gave up to avoid financial strain on their family, 'This work is too stressful for me... I do want a lighter job... We do not have much savings left now. Alas. Very little [money]. [sigh] So I feel stressed. The kids will continue to study for a two year graduate degree and they will work, then I need to consider their marriage' (11101, male).

\section{Traditional social roles}

Based on gender stereotypes, traditional social roles in Chinese culture include traditional family roles and career roles.

Generally, women and men play different family roles and shoulder various responsibilities in the Chinese family. Men are more likely to earn money and support the family financially, while women take more time to do housework and take care of children. Eight participants identified traditional social roles as associated with multiple role conflicts. It seems that women suffer less due to family financial burden and experience less individual health and work conflicts. As a female participant described, 'When I was diagnosed with CHB, I was forced to stop working in the factory. My husband told me that I did not need to work and suggested that I stay at home [look after the kid and do housework]. So I did not worry too much' (23101, female). In contrast, a male participant stated, 'It is harmful for health. So I have to think whether I should continue this job or not. I don't want to do this job any more. [silence] But when I calm down, if I don't work, as the primary breadwinner of my family, as a father, I still have two children [to raise]' (11101, 
male). It was supposed that men would experience more individual health-work conflicts than women due to their work roles. A female participant reported, 'You must drink even though you can't drink.... In that situation, you are not allowed to say you cannot drink.... Nevertheless, you are a woman. If you were a man, drinking avoidance is not easy, right? [laugh]' (11103, female).

\section{Work environment}

The work environment is important for time management, including work time, work tasks and supervisor support. Flexible work time and work tasks are positively related to autonomy at work and the control of time. In a flexible work condition, people will meet fewer timeincompatible problems and have less work stress, thus reducing time-based conflicts and strain-based conflicts effectively: 'I don't need to go to work at nine o'clock in the morning and finish at five. Regardless, freedom and creativity play a key role in my job. Compared with other jobs, I feel my work is more relaxing' (13303, male). Moreover, a high level of supervisor support is positively associated with fewer time-based conflicts as well: 'Working in the factory is also unconstrained. Other people work at $7: 30$ every day, but I arrive at the factory at 8 o'clock. The factory treats me nice' (23101, female).

\section{DISCUSSION}

The participants recruited in our study experienced timebased, strain-based and behaviour-based WHPLCs, owing to contextual factors involving personal characteristics, financial strain, traditional social role and work environment. These findings are a critical first step in identifying the risk of work-related, health-related and personal liferelated problems and in developing tailored interventions to achieve role balance.

\section{Conflicts emerged between sick roles and other social roles}

Time-based conflicts were usually associated with the discrepancy between work time requirements (such as excessive work time, shift work and inflexible work schedules) and enough rest required by the sick roles. A Japanese study found that patients with CHB faced employment-related difficulties owing to the limited time resources, and some of them were demoted or forced to quit their jobs. ${ }^{29}$ Unbefitting working hours were also reported to interfere with family life as well. ${ }^{53-55}$ Gignac et $a t^{23}$ reported that work and personal demands sometimes interfered with the time needed to care for arthritis, including scheduling healthcare appointments and getting rest. However, illness-related symptoms could interfere with work concentration and productivity, which further led to reduced time efficiency. Patients living with chronic diseases viewed fatigue as the main factor limiting their job opportunity and work capacity, ${ }^{23} 5657$ which was consistent with our findings. The awareness of fatigue itself stressed the participants in our study who were pursuing career development and negatively influenced their work performance further, which was also in agreement with previous evidence from a study focused on patients with rheumatic diseases. ${ }^{41}$

HBV infection has been identified as a barrier in work and social life by many studies but mostly from the angle of disease prejudice and discrimination/ stigma. ${ }^{25} 4758{ }^{59}$ Fatigue was only considered by doctors as a physical symptom along with nausea and digestion difficulties. ${ }^{25475859}$ However, few studies have investigated the impacts of fatigue on work and social lives among patients with CHB. The findings of this study add to the literature on how the sick roles, which require the avoidance of fatigue, physically and mentally impacted the work and family lives of patients with CHB.

Strain-based conflicts in this study usually arose from strain concerning CHB-related stigma experienced in work and other social roles. Patients living with CHB bore extensive social implications in the Chinese context, such as limited access to education and employment and difficulty in marriage and intimate relationships. ${ }^{2547}$ Negative feelings and mental stress can stem from patients' past experience of discrimination resulting in a 'shadow' that has a 'lasting' impact on how they perceive themselves. ${ }^{60}$ Of the three types of role conflicts, strain-based conflicts are the most likely to harm relationships outside of work, ${ }^{61}$ and lead to sleeping difficulties, exhaustion, irritability and social withdrawal. ${ }^{62}$ The emotional symptoms found in these participants, such as confusion and anxiety, are consistent with previous studies. ${ }^{63} 64$ Recent evidence suggests that the counselling provided by clinicians can help patients on long-term sick leave relieve negative attitudes and thoughts, sort out the obstacles to getting back to work and consequently facilitate the balance of daily life roles. ${ }^{65}$ Therefore, to improve the psychological status and relieve negative feelings and mental stress, interventions with psychological counselling should be part of the healthcare for treatment-naive patients with CHB.

Specific patterns of behaviour required in one role may be incompatible with expectations regarding behaviour in another role, resulting in behaviour-based conflicts. ${ }^{52}$ Mohamed et a ${ }^{66}$ pointed out that cessation of alcohol and smoking, dietary changes and exercise changes were the most common lifestyle changes among patients with CHB. However, our study found that maintaining a healthy lifestyles for patients with CHB on treatment was always against their social-related behaviour required by work life and personal life roles. Similarly, in other illness experience studies, alcohol reduction and fatty food avoidance were regarded as a burden by patients with CHB. ${ }^{50}{ }^{67}$ Taking drinking as an example, drinking is a normal part of work life and served to improve social relationships in many cultures. ${ }^{68} \mathrm{~A}$ study showed that drinking with colleagues after work has a positive impact on fostering harmony among colleagues and on deciding who will be in charge of group collaborations. ${ }^{69}$ In addition, in China's alcohol drinking culture, a person will make others feel that he or she is a 'wet blanket' and hard to cooperate with if he or she refuses to drink during 
a banquet. ${ }^{70}$ Men who are incapable of consuming a large quantity of alcohol are perceived as not masculine enough, ${ }^{71} 72$ which harms the development of a good relationship in the work and personal life domains. As discussed above, Chinese alcohol consumption is not just about enjoying the flavour of alcohol but also exploiting its utility for communication and building social bonds in work relationships and friendships. ${ }^{73-75}$ In the current study, participants who experienced such behaviour-based conflict also reported social withdrawal, such as refusing to attend meet-ups with friends or business banquets. A similar situation exists with smoking as well, owing to the social practices of cigarette gifting and sharing, which contribute to smoking initiation and failure to quit smoking in the Chinese context. ${ }^{76} 77$ These findings on the incompatibility between the demands of physical health and social life (work and personal life) helped us better understand why it was hard for some patients with CHB to follow doctors' advice about a healthy lifestyle in the Chinese context.

\section{How to balance WHPLCs}

Our results indicated that positive cognitive factors and specific competencies were associated with the coping strategies of patients with CHB in terms of appropriate self-identification of sick roles and adaptation to society, which helped them reduce strain-based conflicts and better cope with behaviour-based conflicts. As other studies have shown, positive framing and a spirit of dedication are essential for having healthier behaviour and a better mood. ${ }^{5078}$ Nevertheless, few studies have addressed the effects of specific competencies, including effective problem-solving skills and social skills. In our study, individuals with high problem-solving skills and social skills can buffer behaviour-based conflicts. Such skill training needs to be more considered more in health promotion to relieve behaviour-based conflicts.

Antiviral therapy is an effective but almost lifelong treatment, which results in a huge economic burden and psychological stress to both patients and their families. ${ }^{79}$ In China, as the disease progresses, the direct costs of CHB and its related diseases exceed $40 \%$ of household annual income,$^{80}$ and only a small proportion of patients with CHB have ever accessed treatment, with barriers including limited reimbursement and medical resources. ${ }^{2581}$ In our study, we found that the financial strain had a significant influence on health-seeking behaviour, such as treatment delay. A possible explanation might be that the therapeutic schedules of some patients with CHB are dominated by economic factors rather than clinical outcomes, owing to inadequate reimbursement and low family income in China. Financial responsibility for other family members can cause financial strain as well. ${ }^{82}$ However, the participants who delayed antiviral therapy usually felt guilty about negative health consequences, which strengthened the strain-based conflicts. Taking the above into consideration, the government should formulate a special insurance reimbursement policy to provide low-price drugs for patients with CHB in need of treatment to start antiviral therapy in a timely manner.

Traditional family roles were found to affect multiple role conflicts together with financial strain in this study, notably in married participants with children. The relationship among gender, household income and role conflicts in patients with chronic diseases has been reported previously. Gignac et $\mathrm{al}^{32}$ and Kobayashi $e t a l^{83}$ indicated that women suffered more negative impacts in terms of work-family conflicts from their chronic medical condition due to their responsibility for taking care of children or for family activities and obligations than men. In contrast to earlier studies, our findings suggest that male participants in this study suffered substantial family financial pressure and reported more individual healthwork conflicts. This discrepancy may be attributed to different cultural contexts: men bear more responsibility for career success and family income in China, ${ }^{84}$ and grandparents sometimes help to shoulder the responsibility for grandchildren, which reduces the work-family conflicts of women. ${ }^{85}$ For such male treatment-naive patients with $\mathrm{CHB}$, family support becomes important to help them achieve role balance, reduce stress and thus improve their adherence.

Hämmig and Bauer argued that physical working conditions such as a tiring posture at work and psychosocial working conditions such as time pressure are crucial risk factors for self-rated general health. ${ }^{86}$ Analogously, we found that flexible work time and work tasks somehow form a 'fitting' work environment, which can help to solve the time incompatibility problems and relieve work pressure. This finding also agrees with an earlier study showing that the work environment plays a vital role in time management, influencing time-based and strainbased conflicts. ${ }^{87}$ In addition, some studies have highlighted the importance of supervisor support to prevent both coworker conflicts and supervisor conflicts. ${ }^{88}$ High supervisor support is also positively associated with work time control. However, the work environment varies across different worksites and employment types, ${ }^{89}$ and it is difficult to change the work environment to resolve role conflicts.

\section{Strengths and limitations}

Previous studies have focused on the negative effect of chronic non-communicable diseases on work and personal life, ${ }^{32} 9091$ and less attention has been paid to individuals living with chronic infectious disease. More importantly, as a special social role, the sick role is a health condition and the sum of the patient's social status, rights and obligations. ${ }^{92}$ Our study is one of the few to focus on the conflicts that emerged between sick roles and other social roles (ie, work and personal life roles) in treatment-naive patients with CHB. We found associations of time-based, strain-based and behaviour-based conflicts in different life spheres and identified four contextual factors. Because possible incompatibility and conflicts generated from lifestyle change and other aspects of life 
among treatment-naive patients with CHB have received little attention in existing interventions in China, ${ }^{48} 49$ the findings of this study provide a new perspective of role conflicts to guide psychological counselling for this population, especially at the beginning of antiviral therapy.

Several limitations should be noted, however. First, there were no significant differences in WHPLCs among the six sampled cities with different socioeconomic levels. A possible explanation might be that the impact of city socioeconomic factors may be less likely to be observed than that of individual economic factors via only face-toface interviews concerning disease-related experiences. Second, we recruited participants with help from doctors and other healthcare staff, which might cause selection bias because patients with good adherence were more likely to be included than those with poor adherence. Third, qualitative studies in this study can only observe conflicts and possible associations rather than the magnitude and causality of these associations for which further studies are needed.

\section{CONCLUSION}

The findings of our study enhance our understanding of the WHPLCs experience of treatment-naive patients with $\mathrm{CHB}$ in the Chinese context. These findings imply that multidimensional role conflicts should be taken into account in intervention design and psychological counselling to improve the well-being of this population. Associations among the three types of role conflicts need to be further examined.

\section{Author affiliations}

${ }^{1}$ Department of Social Medicine of School of Public Health, Zhejiang University School of Medicine, Hangzhou, Zhejiang, China

${ }^{2}$ Department of Pharmacy of the First Affiliated Hospital, Zhejiang University School of Medicine, Hangzhou, Zhejiang, China

${ }^{3}$ Department of Health Services, University of Washington, Seattle, Washington, USA

${ }^{4}$ Department of Public Health, Xi'an Medical University, Xi'an, Shaanxi, China

Acknowledgements We would like to express our gratitude to clinical professionals for their help in recruitment. We would also like to thank all of the patients for their participation.

Contributors HW, DP and LZ conceived and designed the study. YZ, LZ, YL and XL drafted the interview guideline. Then $\mathrm{LZ}, \mathrm{YL}, \mathrm{MS}$ and $\mathrm{XC}$ conducted the interviews. Audio-taped interviews were transcribed by FX, LZ, BC and YC. YZ and LZ coded, respectively, then $Y Z, L Z, M S$ and $X C$ analysed the data and then $Y Z$ drafted the paper. All other authors provided constructive comments and revised the manuscript. All authors reviewed and approved the final version of the article.

Funding This work was supported by National Natural Science Foundation of China (grant number: 71573226).

Competing interests None declared.

Patient and public involvement Patients and/or the public were not involved in the design, or conduct, or reporting, or dissemination plans of this research.

Patient consent for publication Not required.

Ethics approval Ethics approval was obtained from Zhejiang University School of Medicine Ethics Committee (Approval No. 2015-026). We obtained written consents from the participants before interviews started.

Provenance and peer review Not commissioned; externally peer reviewed.

Data availability statement № data are available. There are no other data available.
Open access This is an open access article distributed in accordance with the Creative Commons Attribution Non Commercial (CC BY-NC 4.0) license, which permits others to distribute, remix, adapt, build upon this work non-commercially, and license their derivative works on different terms, provided the original work is properly cited, appropriate credit is given, any changes made indicated, and the use is non-commercial. See: http://creativecommons.org/licenses/by-nc/4.0/.

ORCID iD

Hongmei Wang http://orcid.org/0000-0002-7565-9040

\section{REFERENCES}

1 Kahn RL, Wolfe DM, Quinn RP, et al. Organizational stress: studies in role conflict and ambiguity. Oxford, England: John Wiley, 1964.

2 Casper WJ, Harris C, Taylor-Bianco A, et al. Work-family conflict, perceived supervisor support and organizational commitment among Brazilian professionals. J Vocat Behav 2011;79:640-52.

3 Simunic A, Gregov L, Prorokovic A. The discrepancy between values and their achievement, work-family conflict, and satisfaction in dualcareer couples. Advances Business-Related Res J 2011;2:169-80.

4 Knežević I, Gregov L, Šimunić A. Salience and conflict of work and family roles among employed men and women. Arh Hig Rada Toksikol 2016;67:152-63.

5 Liu J, Lambert EG, Kelley T, et al. Exploring the association between work-family conflict and job involvement. Int $J$ Offender Ther Comparative Criminolog 2019.

6 Acker J. Theorizing gender, race, and class in organizations. In: Jeanes EL, Knights D, Martin PY, eds. Handbook of gender, work \& organization. Chichester: Wiley, 2011.

7 Takacs J. Unattainable desires? Childbearing capabilities in early 21st century Hungary. In: Oláh LS, Fratczak S, eds. Childbearing, Women's Employment and Work-Life Balance Policies in Contemporary Europe. London: Palgrave Macmillan, 2013: 179-206.

8 Jensen MT. A two wave cross-lagged study of work-role conflict, work-family conflict and emotional exhaustion. Scand J Psychol 2016;57:591-600.

9 Jensen MT. Exploring business travel with work-family conflict and the emotional exhaustion component of burnout as outcome variables: the job demands-resources perspective. Eur J Work Organizational Psychol 2014;23:497-510.

10 Karkkola P, Kuittinen M, Hintsa T. Role clarity, role conflict, and vitality at work: the role of the basic needs. Scand J Psychol 2019;60:456-63.

11 Major VS, Klein KJ, Ehrhart MG. Work time, work interference with family, and psychological distress. J Appl Psychol 2002;87:427-36.

12 Aazami S, Akmal S, Shamsuddin K. A model of work-family conflict and well-being among Malaysian working women. Work 2015;52:687-95.

13 Bowen P, Govender R, Edwards P, et al. Work-related contact, work-family conflict, psychological distress and sleep problems experienced by construction professionals: an integrated explanatory model. Construct Manage Eco 2018;36:153-74.

14 Specht JA. Mentoring relationships and the levels of role conflict and role ambiguity experienced by novice nursing faculty. J Prof Nurs 2013;29:e25-31.

15 Westring AF, Speck RM, Dupuis Sammel M, et al. Culture matters: the pivotal role of culture for women's careers in academic medicine. Acad Med 2014;89:658-63.

16 Liu J, Lambert EG, Jiang S, et al. A research note on the association between work-family conflict and job stress among Chinese prison staff. Psychol Crime Law 2017;23:633-46.

17 Griep $\mathrm{RH}$, Toivanen S, van Diepen C, et al. Work-family conflict and self-rated health: the role of gender and educational level. baseline data from the Brazilian longitudinal study of adult health (ELSABrasil). Int J Behav Med 2016;23:372-82.

18 Zheng J, Wu G. Work-family conflict, perceived organizational support and professional commitment: a mediation mechanism for Chinese project professionals. Int J Environ Res Public Health 2018;15:344.

19 Parsons T. The social system. Glencoe, IL: The Free Press, 1951: 428-47.

20 Frank AW. From sick role to practices of health and illness. Med Educ 2013;47:18-25.

21 Frank AW. From sick role to narrative subject: an analytic memoir Health 2016;20:9-21.

22 Gignac MAM, Backman CL, Davis AM, et al. Social role participation and the life course in healthy adults and individuals with osteoarthritis: are we overlooking the impact on the middle-aged? Soc Sci Med 2013;81:87-93. 
23 Gignac MAM, Backman CL, Kaptein S, et al. Tension at the borders: perceptions of role overload, conflict, strain and facilitation in work, family and health roles among employed individuals with arthritis. Rheumatology 2012;51:324-32.

24 Varul MZ. Talcott Parsons, the sick role and chronic illness. Body Soc 2010;16:72-94.

25 Wallace J, Pitts M, Liu C, et al. More than a virus: a qualitative study of the social implications of hepatitis B infection in China. Int J Equity Health 2017:16:137.

26 Gignac MAM, Cao X, Tang K, et al. Examination of arthritis-related work place activity limitations and intermittent disability over four-and-a-half years and its relationship to job modifications and outcomes. Arthritis Care Res 2011;63:953-62.

27 Kaptein SA, Backman CL, Badley EM, et al. Choosing where to put your energy: a qualitative analysis of the role of physical activity in the lives of working adults with arthritis. Arthritis Care Res 2013:65:1070-6.

28 Siu JY-M. Imprisoned in the cultural stereotypes of overactive bladder: cultural meanings of disease and sick role adaptation in Hong Kong. Nurs Res 2016;65:352-61.

29 Oka T, Enoki H, Tokimoto Y, et al. Employment-related difficulties and distressed living condition in patients with hepatitis B virus: a qualitative and quantitative study. BMC Public Health 2017;17:568.

30 de Ridder D, Geenen R, Kuijer R, et al. Psychological adjustment to chronic disease. Lancet 2008;372:246-55.

31 Frone MR, Russell M, Barnes GM. Work-family conflict, gender, and health-related outcomes: a study of employed parents in two community samples. J Occup Health Psychol 1996;1:57-69.

32 Gignac MAM, Lacaille D, Beaton DE, et al. Striking a balance: work-health-personal life conflict in women and men with arthritis and its association with work outcomes. J Occup Rehabil 2014;24:573-84

33 de Franchis R, Hadengue A, Lau G, et al. EASL international consensus conference on hepatitis B. 13-14 September, 2002 Geneva, Switzerland. consensus statement (long version). $J$ Hepatol 2003;39(Suppl 1):S3-25.

34 Lu F-min, Zhuang H. Management of hepatitis B in China. Chin Med J 2009;122:3-4.

35 Hou J, Wang G, Wang F, et al. Guideline of prevention and treatment for chronic hepatitis B (2015 update). J Clin Transl Hepatol 2017:5:297-318.

36 World Health Organization. Guidelines for the prevention, care and treatment of persons with chronic hepatitis B infection. Geneva: World Health Organization, 2015. https://www.who.int/hepatitis/ publications/hepatitis-b-guidelines/en/

37 Terrault NA, Lok ASF, McMahon BJ, et al. Update on prevention, diagnosis, and treatment of chronic hepatitis B: AASLD 2018 hepatitis B guidance. Hepatology 2018;67:1560-99.

38 Humeniuk R, Henry Edwards S, Robert A, et al. The alcohol, smoking and substance involvement screening test (ASSIST): manual for use in primary care. Geneva: World Health Organization 2010: 103. 1039--47. https://apps.who.int/iris/handle/10665/44320

39 Gignac MAM, Jetha A, Bowring J, et al. Management of work disability in rheumatic conditions: a review of non-pharmacological interventions. Best Pract Res Clin Rheumatol 2012;26:369-86.

40 Gignac MAM, Ibrahim S, Smith PM, et al. The role of sex, gender, health factors, and job context in workplace accommodation use among men and women with arthritis. Ann Work Expo Health 2018;62:490-504.

41 Connolly D, Fitzpatrick C, O'Toole L, et al. Impact of fatigue in rheumatic diseases in the work environment: a qualitative study. Int $J$ Environ Res Public Health 2015:12:13807-22.

42 Chen XB, Gong ZJ, Yang LH. An evaluation on quality of life in patients with chronic hepatitis $B$ after antiviral therapy: health questionnaire survey. Chin J Infect Dis 2006;24:44-8.

43 Shi M, XT M, Lin B, et al. Study on quality of life and its related factors among patients with chronic hepatitis B. Chin J Infect Dis 2016;34:267-70.

44 Hajarizadeh B, Richmond J, Ngo N, et al. Hepatitis B-related concerns and anxieties among people with chronic hepatitis $B$ in Australia. Hepat Mon 2016;16:e35566.

45 Le TV, Vu TTM, Mai HT, et al. Social determinants of stigma and discrimination in Vietnamese patients with chronic hepatitis B. Int J Environ Res Public Health 2019;16:E398.

46 Zhuang G, Zhang M, Liu Y, et al. Significant impairment of healthrelated quality of life in mainland Chinese patients with chronic hepatitis B: a cross-sectional survey with pair-matched healthy controls. Health Qual Life Outcomes 2014;12:101.

47 Han B, Yuan Q, Shi Y, et al. The experience of discrimination of individuals living with chronic hepatitis $B$ in four provinces of China. PLoS One 2018;13:e0195455.
48 Zhou J, Meng QJ, Shi YX. The effects of Patient-family synchronous health education on the quality of life of patients with chronic hepatitis B. Chin General Nurs 2010;8:180.

49 Zhang J. Psychotherapy in chronic hepatitis B patients' rehabilitation (Doctoral dissertation). Shandong: Shandong University, 2005. http:// www.wanfangdata.com.cn/details/detail.do?_type=degree\&id= Y971315

50 Taheri Ezbarami Z, Hassani P, Zagheri Tafreshi M, et al. A qualitative study on individual experiences of chronic hepatitis B patients. Nurs Open 2017:4:310-8.

51 Braun V, Clarke V. Successful qualitative research: a practical guide for beginners. SAGE, 2013.

52 Greenhaus JH, Beutell NJ. Sources of conflict between work and family roles. Acad Management Rev 1985;10:76-88.

53 Lambert EG, Qureshi H, Frank J, et al. The relationship of work-family conflict with job stress among Indian police officers: a research note. Police Pract Res 2017;18:37-48.

54 Pleck JH, Staines GL, Lang L. Conflicts between work and family life. Monthly Labor Review 1980;103:29-32.

55 Thomas LT, Ganster DC. Impact of family-supportive work variables on work-family conflict and strain: a control perspective. J Appl Psychol 1995;80:6-15.

56 Feldthusen C, Björk M, Forsblad-d'Elia $\mathrm{H}$, et al. Perception, consequences, communication, and strategies for handling fatigue in persons with rheumatoid arthritis of working age--a focus group study. Clin Rheumatol 2013;32:557-66.

57 Gignac MAM, Sutton D, Badley EM. Reexamining the arthritisemployment interface: perceptions of arthritis-work spillover among employed adults. Arthritis Rheum 2006;55:233-40.

58 Jang Y, Boo S, Yoo H. Hepatitis B virus infection: FatigueAssociated illness experiences among Koreans. Gastroenterol Nurs 2018;41:388-95.

59 Valizadeh L, Zamanzadeh V, Zabihi A, et al. Qualitative study on the experiences of hepatitis B carriers in coping with the disease. Jpn J Nurs Sci 2019;16:194-201.

$60 \mathrm{Na} \mathrm{L}, \mathrm{Na} \mathrm{B}$. A revolutionary road: an analysis of persons living with hepatitis B in China. J Health Commun 2013;18:71-91.

61 Lambert EG, Qureshi H, Frank J. Spilling over: an exploratory study of the correlates of strain-based work-family conflict among police officers in India. Int J Police Sci Manage 2016;18:87-103.

62 Kinman G. Emotional labour and strain in "front-line" service employees: Does mode of delivery matter? J Managerial Psychol 2009;24:118-35.

63 Modabbernia A, Ashrafi M, Malekzadeh R, et al. A review of psychosocial issues in patients with chronic hepatitis B. Arch Iran Med 2013;16:114-22.

64 Liu Y, Tang K, Long J, et al. The association between hepatitis B self-awareness and depression: exploring the modifying effects of socio-economic factors. J Viral Hepat 2017;24:330-6.

65 Eftedal M, Kvaal AM, Ree E, et al. How do occupational rehabilitation clinicians approach participants on long-term sick leave in order to facilitate return to work? A focus group study. BMC Health Serv Res 2017; $17: 744$.

66 Mohamed R, Ng CJ, Tong WT, et al. Knowledge, attitudes and practices among people with chronic hepatitis $\mathrm{B}$ attending a hepatology clinic in Malaysia: a cross sectional study. BMC Public Health 2012;12:601.

67 Adjei CA, Naab F, Donkor ES. Beyond the diagnosis: a qualitative exploration of the experiences of persons with hepatitis $B$ in the Accra Metropolis, Ghana. BMJ Open 2017;7:e017665.

68 Janes CR, Ames G. Men, blue collar work and drinking: alcohol use in an industrial subculture. Cult Med Psychiatry 1989;13:245-74.

69 Hagihara A, Tarumi K, Nobutomo K. Work stressors, drinking with colleagues after work, and job satisfaction among white-collar workers in Japan. Subst Use Misuse 2000;35:737-56.

70 Zhou L, Zhang G, Hu H, et al. Perceived interpersonal pressure and drinking behavior in South China. Drug Alcohol Depend 2013;130:122-8.

71 Jiafang Z, Jiachun W, Yunxia L, et al. Alcohol abuse in a metropolitan City in China: a study of the prevalence and risk factors. Addiction 2004;99:1103-10.

72 Wei H, Hao W. Alcohol policy and the public good: a Chinese view. Addiction 1995;90:1448-50.

73 Jiang L. Comparison of the difference between Chinese and Western drinking culture. Asian Soc Sci 2011;7:251-7.

74 H.X H, Liu TQ, Hao W. The difference in subjective responses to alcohol between heavy and light male social drinkers in China and America. Chin J Drug 2016;25:195-201.

$75 \mathrm{Li} \mathrm{J}$, Wu B, Selbæk G, et al. Factors associated with consumption of alcohol in older adults - a comparison between two cultures, China and Norway: the CLHLS and the HUNT-study. BMC Geriatr 2017;17:172. 
76 Hu M, Rich ZC, Luo D, et al. Cigarette sharing and gifting in rural China: a focus group study. Nicotine Tob Res 2012;14:361-7.

77 Rich ZC, Xiao S. Tobacco as a social currency: cigarette gifting and sharing in China. Nicotine Tob Res 2012;14:258-63.

78 Li H, Sankar A, Holroyd E, et al. Safer sex practices among newly diagnosed HIV-positive men who have sex with men in China: results from an ethnographic study. Int J Qual Stud Health Well-being 2017; $12: 1335167$

79 Xue X, Cai S, Ou H, et al. Health-related quality of life in patients with chronic hepatitis $\mathrm{B}$ during antiviral treatment and off-treatment. Patient Prefer Adherence 2017;11:85-93.

$80 \mathrm{Lu} \mathrm{J}, \mathrm{Xu} \mathrm{A}$, Wang J, et al. Direct economic burden of hepatitis B virus related diseases: evidence from Shandong, China. BMC Health Serv Res 2013;13:37.

81 Yu R, Fan R, Hou J. Chronic hepatitis B virus infection: epidemiology, prevention, and treatment in China. Front Med 2014;8:135-44.

82 Eshak ES, Kamal NN, Seedhom AE, et al. Work-family conflict and self-rated health among dwellers in Minia, Egypt: financial strain vs social support. Public Health 2018;157:69-76.

83 Kobayashi T, Honjo K, Eshak ES, et al. Work-family conflict and self-rated health among Japanese workers: how household income modifies associations. PLoS One 2017;12:e0169903.

84 Xu Q, Qi J. Work-family conflict, gender role, and job satisfaction : An analysis of the phase III Chinese women social status survey. Society 2016;36:192-215.
85 Chen F, Liu G, Mair CA. Intergenerational ties in context: grandparents caring for grandchildren in China. Soc Forces 2011;90:571-94.

86 Hämmig O, Bauer GF. Work, work-life conflict and health in an industrial work environment. Occup Med 2014;64:34-8.

87 Mackenzie CR, Keuskamp D, Ziersch AM, et al. A qualitative study of the interactions among the psychosocial work environment and family, community and services for workers with low mental health. BMC Public Health 2013;13:796.

88 De Raeve L, Jansen NW, van den Brandt PA, et al. Risk factors for interpersonal conflicts at work. Scand J Work Environ Health 2008;34:96-106.

89 Williams JA, Buxton O, Hinde J, et al. Psychosocial workplace factors and healthcare utilization: a study of two employers. Int $J$ Health Policy Manag 2017;7:614-22.

90 Yagasaki K, Komatsu H, Takahashi T. Inner conflict in patients receiving oral anticancer agents: a qualitative study. BMJ Open 2015;5:e006699.

91 Hämmig O, Knecht M, Läubli T, et al. Work life conflict and musculoskeletal disorders: a cross-sectional study of an unexplored association. BMC Musculoskelet Disord 2011;12:60.

92 Duan ZG, Zuxun L. Thoughts on the patient's roles in terms of social psychology. Med Philosophy 2004;25:75-6. 